Check for updates

Cite this: Chem. Sci., 2018, 9, 6860

๑ All publication charges for this article have been paid for by the Royal Society of Chemistry

Received 8th June 2018

Accepted 16th July 2018

DOI: $10.1039 / \mathrm{c} 8 \mathrm{sc} 02532 \mathrm{k}$

rsc.li/chemical-science

\section{Bis-pyrene probes of foldamer conformation in solution and in phospholipid bilayers $\uparrow$}

\author{
Francis G. A. Lister, ${ }^{a}$ Natasha Eccles, ${ }^{\text {ab }}$ Sarah J. Pike, D abc Robert A. Brown, ${ }^{a}$ \\ George F. S. Whitehead, (D) James Raftery, ${ }^{a}$ Simon J. Webb (ID *ab \\ and Jonathan Clayden (D) *d
}

\begin{abstract}
Exploring the detailed structural features of synthetic molecules in the membrane phase requires sensitive probes of conformation. Here we describe the design, synthesis and characterization of bis(pyrene) probes that report conformational changes in membrane-active dynamic foldamers. The probes were designed to distinguish between left-handed $(M)$ and right-handed $(P)$ screw-sense conformers of $3_{10}$-helical $\alpha$-aminoisobutyric acid (Aib) peptide foldamers, both in solution and in bilayer membranes. Several different bis(pyrene) probes were synthesized and ligated to the C-terminus of Aib tetramers that had different chiral residues at the $\mathrm{N}$-terminus, residues that favored either an $M$ or a $P$ screw-sense in the $3_{10}$-helix. The readily synthesized and conveniently incorporated $N$-acetyl-1,2-bis(pyren- $1^{\prime}$-yl) ethylenediamine probe proved to have the best properties. In solution, changes in foldamer screw-sense induced substantial changes in the ratio of excimer/monomer fluorescence emission (E/M) for this reporter of conformation, with X-ray crystallography revealing that opposite screw-senses produce very different interpyrene distances in the reporter. In bilayers, this convenient and sensitive fluorescent reporter allowed, for the first time, an investigation of how the chirality of natural phospholipids affects foldamer conformation.
\end{abstract}

\section{Introduction}

Conformational control of configurationally achiral helical folded oligomers (foldamers) has recently been shown to provide a route to biomimetic nanoscale molecular devices capable of transmitting information over multi-nanometer distances. ${ }^{\mathbf{1}}$ Foldamers composed of $\alpha$-aminoisobutyric acid (Aib) have proven to be particularly promising in this respect. ${ }^{2}$ Aib foldamers with at least four Aib residues can fold into $3_{10}$-helices, in which left-handed $(M)$ and right-handed $(P)$ screw-senses are equally populated owing to the lack of chirality in an Aib residue. ${ }^{3}$ Short Aib foldamers interconvert rapidly between screw-senses on the typical ${ }^{1} \mathrm{H}$ NMR spectroscopy timescale, ${ }^{3 a}$ allowing any induced imbalance in the ratio of $M$ to $P$ helices to

${ }^{a}$ School of Chemistry, University of Manchester, Oxford Road, Manchester M13 9PL, UK. E-mail: S.Webb@manchester.ac.uk

${ }^{b}$ Manchester Institute of Biotechnology, University of Manchester, 131 Princess St, Manchester M1 TDN, UK

${ }^{c}$ Faculty of Life Sciences, University of Bradford, Bradford, West Yorkshire, BD7 1DP, $U K$

${ }^{d}$ School of Chemistry, University of Bristol, Cantock's Close, Bristol BS8 1TS, UK. E-mail: j.clayden@bristol.ac.uk

$\uparrow$ Electronic supplementary information (ESI) available: Synthetic procedures and NMR spectra for new compounds, analytical procedures and data for fluorescence studies and X-ray crystallography data. CCDC 1843678-1843682. For ESI and crystallographic data in CIF or other electronic format see DOI: $10.1039 / \mathrm{c} 8 \mathrm{sc} 02532 \mathrm{k}$ give rise to diagnostic changes in the NMR spectra of appropriately designed foldamers. ${ }^{4}$

The conformational uniformity of Aib oligomers ${ }^{1 e}$ means that a conformational preference induced by a chiral group, a "controller", at one terminus of the helix, propagates throughout the foldamer and leads to an imbalance in the ratio of $M$ and $P$ helical conformers. ${ }^{5}$ Covalent or non-covalent interaction of this controller with the foldamer, typically at its $\mathrm{N}$-terminus, can be viewed as a form of information input. This information, encoded in the conformational preference of the oligomer, can be read at the distal terminus of the foldamer by a group, a "reporter", which is designed to give a diagnostic spectroscopic output.

NMR spectroscopy is a powerful tool for studying conformational interchange and conformational preferences in Aib foldamers in isotropic solution. ${ }^{1} \mathrm{H},{ }^{19} \mathrm{~F}$ and ${ }^{13} \mathrm{C}$ NMR spectroscopic reporters have been incorporated into Aib foldamers, and used to report on conformational control from both the $\mathrm{N}$ and C-termini. ${ }^{5,6}$ For example, a ${ }^{13} \mathrm{C}$ NMR spectroscopic probe was used to report on dynamic exchange of chiral messengers at the N-terminus of a class of boron-containing dynamic foldamer, allowing the development of a synthetic system that functions in organic solvent to mimic the behavior of purinergic receptors. $^{7}$

Nonetheless, true biological receptors in the $G$ protein coupled receptor class function as membrane-embedded 
structures. Transferring foldamer-based biomimetic receptors from organic solvent into a phospholipid bilayer, the environment experienced by most natural receptors, presents several analytical challenges. ${ }^{1} \mathrm{H}$ or ${ }^{13} \mathrm{C}$ signals of NMR-detectable reporters will be masked by signals from lipids, especially as the reporter should be at a low loading in the membrane. The anisotropic membrane environment will also broaden NMR signals. We have shown that ${ }^{19} \mathrm{~F}$ NMR spectroscopy ${ }^{6 c}$ with magic-angle spinning can overcome these problems to some extent, but the spectral acquisition times are long, high concentrations of multilamellar vesicles are required, and samples must be spun rapidly before spectral acquisition, preventing real-time detection of conformational changes. ${ }^{8} \mathrm{~A}$ more biomimetic system would use unilamellar vesicles with distinct interior and exterior environments. To explore the function of dynamic foldamers in intact unilamellar vesicles, alternative spectroscopic techniques were needed.

Fluorescent probes are compatible with membrane environments and can report on changes in orientation and distance between chromophores, ${ }^{9}$ for example through Förster resonance energy transfer, reversible electronic energy transfer ${ }^{\mathbf{1 0}}$ and excimer formation. ${ }^{\mathbf{1 1}}$ We recently reported a successful application of fluorescent reporters of dynamic conformational change in a membrane environment, ${ }^{12}$ and we now describe in detail the design, development and analysis of membranecompatible fluorescent probes of conformation.

We opted to explore the use of excimer emission from pyrene chromophores. ${ }^{13}$ The emission spectrum of pyrene varies according to its proximity to other pyrene moieties. When two pyrene molecules are less than $\sim 10 \AA$ apart, an excited dimer (excimer) can form that has broad emission at longer wavelengths (425-550 nm). ${ }^{\mathbf{1 4}}$ Incorporating two pyrene rings (Pyr, Fig. 1a) into a fluorescent reporter group may allow conformational changes in the reporter to vary the distance between the pyrene rings, modulating the intensity of the excimer emission.

Since screw-sense conformers are enantiomeric, any conformational changes induced in an achiral reporter would not give rise to a change in conventional fluorescence emission spectra. A chiral reporter would nonetheless give rise to diastereoisomeric conformers with different emission properties, allowing fluorescence spectroscopy to report on changes in screw-sense preference. However, the use of a chiral reporter brings with it a potential problem, as it must be conformationally responsive without exerting a strong chiral influence over the foldamer helix. Provided also that intermolecular excimer formation is avoided, such probes would be powerful tools that can report on conformational change in both solution and membrane phases. By correlating these changes in fluorescence with established data from NMR spectroscopy, a quantitative interpretation of the fluorescence changes should be possible.

\section{Results and discussion}

Our strategy for the development of bis(pyrene) probes is illustrated in Fig. 1a. A successful probe would exhibit detectable differences in the ratio of excimer to monomer emission a)

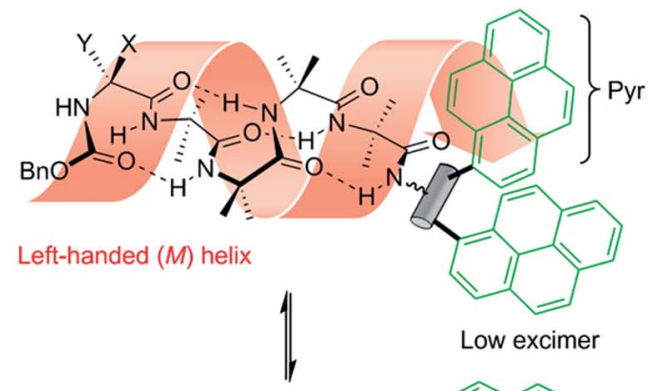

Right-handed $(P)$ helix

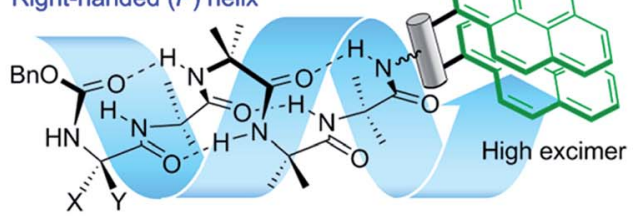

(P) helical excess

D-Phe controller $\mathrm{X}=\mathrm{H}, \mathrm{Y}=\mathrm{CH}_{2} \mathrm{Ph}$ L- $\alpha$ MeVal controller $\mathrm{X}=\mathrm{CHMe}_{2}, \mathrm{Y}=\mathrm{Me}$

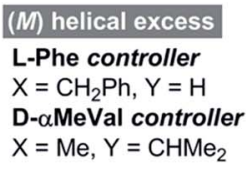

b)<smiles>CC(CBr)C(=O)NCCBr</smiles><smiles>[R][R]1=CC=[R]([H])C1</smiles>

d)
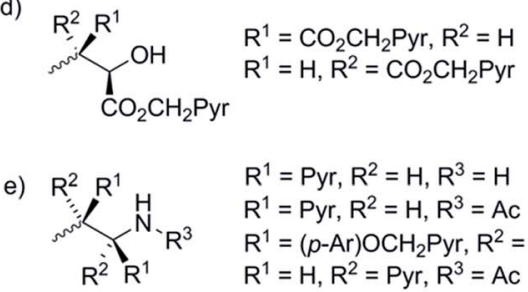

$\mathrm{R}^{1}=\mathrm{Pyr}, \mathrm{R}^{2}=\mathrm{H}, \mathrm{R}^{3}=\mathrm{H}$

$R^{1}=P y r, R^{2}=H, R^{3}=A C$

$\mathrm{R}^{1}=(p-\mathrm{Ar}) \mathrm{OCH}_{2} \mathrm{Pyr}, \mathrm{R}^{2}=\mathrm{H}, \mathrm{R}^{3}=\mathrm{H}$ $R^{1}=H, R^{2}=$ Pyr, $R^{3}=A c$

Fig. 1 Development of chiral, conformationally responsive fluorescent probes. Pyr $=$ pyren-1-yl. $p$-Ar $=1,4$-disubstituted benzene. (a) Schematic bis(pyren-1-yl) probe attached to $M$ and $P$ screw-sense conformers of a controlled $\mathrm{Aib}_{4}$ helix; (b), (c) reporters incorporating one or two pyrenylalanine (Pya) residues; (d) reporters derived from aminoalcohol probes; (e) reporters derived from 1,2-bis(aryl)ethylenediamine probes.

( $E / M$ ratio) when ligated to the C-terminus of a foldamer helix carrying a range of $\mathrm{N}$-terminal chiral controllers with different abilities to favor either $M$ or $P$ screw-senses. An $\mathrm{Aib}_{4}$ helical foldamer scaffold was selected, as $\mathrm{Aib}_{4}$ is rapidly synthetically accessible yet long enough to fold into a single turn $3_{10}$-helix. It is also long enough to prevent direct, rather than conformationally relayed, interaction between chiral controller and reporter. ${ }^{5}$ Furthermore, a wide range of chiral controllers, such as $\mathrm{Cbz}\left(\alpha\right.$-methylvaline) $[\mathrm{Cbz}(\alpha-\mathrm{MeVal})]{ }^{1 e}$ have been covalently attached to the N-terminus of $\mathrm{Aib}_{4}$ foldamers and the extent to which they each favor either $M$ or $P$ helical conformations has been quantified by NMR spectroscopy; ${ }^{5}$ this provides data for the calibration of the fluorescent response from bis(pyrene) probes.

$\mathrm{Aib}_{4}$ foldamers with a defined screw-sense preference arising from chiral N-terminal residues, along with achiral Aib $_{4}$ 
foldamers as control compounds, were ligated to three generations of bis(pyrene) probes (Fig. 1b-e). The first generation of probes were formed from pyrenylalanine, with the second generation derived from L-tartrate and the third generation based upon 1,2-bis(aryl)ethylenediamine building blocks. All of these probe designs have the potential to donate hydrogen bond(s) back into the $3_{10}$-helix, increasing the likely sensitivity of their conformational preference to the sense of the helix. The most promising probes were then optimized and subsequently used in bilayer studies.

\section{Development of pyrenylalanine-based probes}

A simple way to functionalize an Aib foldamer helix with pyren1-yl groups was to incorporate adjacent 3-(pyren-1'-yl)alanine (Pya) residues (Fig. 1b and c). Synthetic routes to Pya are well documented, ${ }^{15}$ and Sisido et al. have incorporated Pya into helical structures both as poly(L-Pya ${ }^{16}$ and as a bis-Pya label in the backbone of a short $\alpha$-helical polymer. ${ }^{17}$ Dimers of Pya were used by De Schryver and coworkers to analyze dipeptide conformations. ${ }^{\mathbf{1 5 c , 1 8}}$ Encouraged by these prior studies, diastereoisomeric dimers 4 and 5 , along with 3-(pyren-1'-yl)alanine (pyren-1'-ylmethyl)amide $\mathbf{6}$ were our first probe targets.

$\mathrm{L}^{-}$and D-isomers of $\mathrm{N}$-BocPya methyl ester were synthesized following the procedures of Egusa et al. ${ }^{19}$ which first provided Land D-Pya in $80 \%$ and $94 \%$ ee respectively. Subsequent protection, as a methyl ester to give 2 or as the $N$-Boc derivative to give 1, was followed by coupling to give target probes 4,5 and 6 (Scheme 1a). $N$-Deprotection gave poorly soluble dipeptides or amides that were coupled directly to the C-terminus of

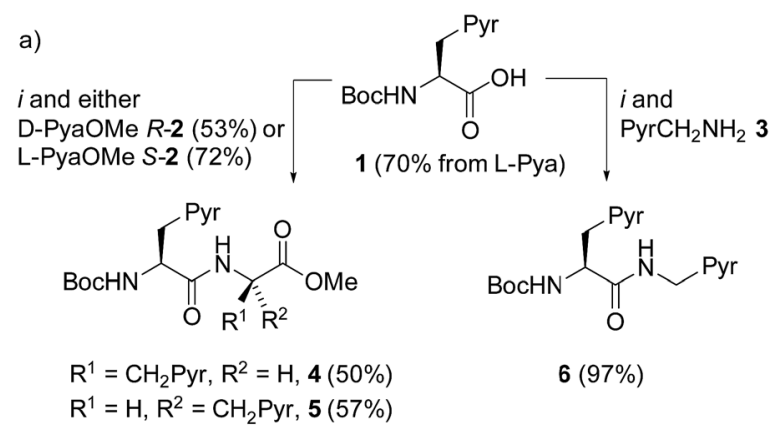

b)

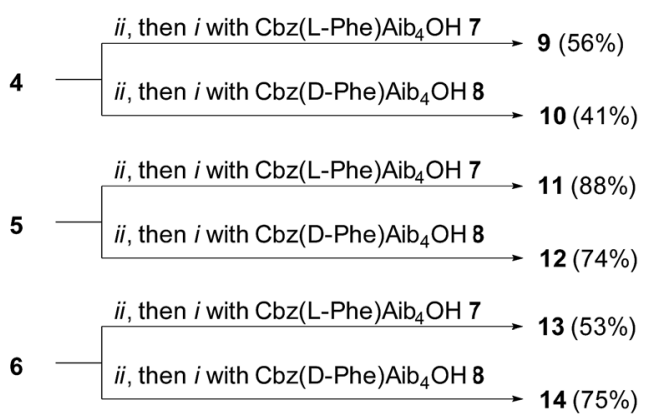

Scheme 1 (a) Synthesis of 'first generation' probes 4-6. Pyr = pyren1-yl. (i), EDC, HOBt, i- $\mathrm{Pr}_{2} \mathrm{NEt}, \mathrm{CH}_{2} \mathrm{Cl}_{2}$, RT. (b) Synthesis of foldamers 914 bearing first generation probes. (ii), $\mathrm{TFA} / \mathrm{CH}_{2} \mathrm{Cl}_{2}$. enantiomeric $\mathrm{CbzPheAib}_{4} \mathrm{OH}$ helices to give three pairs of diastereoisomeric foldamers 9-14 (Scheme 1).

Two problems were immediately evident with these 'first generation' structures. Firstly, no excimer fluorescence was detectable from any of these compounds (see the $\operatorname{ESI}_{\dagger}^{\dagger}$ ). Furthermore, circular dichroism spectra from each member of the three diastereoisomeric pairs were almost identical, indicating that their conformation was similar, despite the opposite absolute configuration of the N-terminal controller. This implies that, despite the reported dominance of $\mathrm{N}$ - over $\mathrm{C}$ terminal controllers, ${ }^{20}$ the conformational preference imparted by these chiral fluorescent probes is too powerful, overpowering the influence of the N-terminal CbzPhe residue.

The X-ray crystal structure of $\mathbf{1 3}$ (Fig. 2) supported this interpretation. The $\mathrm{Aib}_{4}$ helix adopts a right-handed conformation as a consequence of the single C-terminal $\mathrm{L}$-Pya residue, with the L-Phe incorporated into a type III $\beta$-turn, rather than the left-handed helical conformation typically induced by an $\mathrm{N}$ terminal $\mathrm{Cbz}(\mathrm{L}-\mathrm{Phe})$ residue in a type II $\beta$-turn., ${ }^{\mathbf{4 , 2 1}}$

The lack of excimer fluorescence from the first generation probes prompted us to explore structures with the pyren-1-ylbearing groups closer to each other, separated by a single rotatable bond. Such 1,2-difunctionalised motifs are available either from the natural chiral pool (e.g. by transformation of $\mathrm{L}^{-}$ tartrate) or by asymmetric synthesis.

\section{Development of 1,2-aminoalcohol-based probes}

A C-terminal chiral aminoalcohol reporter (Fig. 1d) derived from probe 15 (Scheme 2) would have a structure similar to the probe used by Koert and coworkers to detect conformational

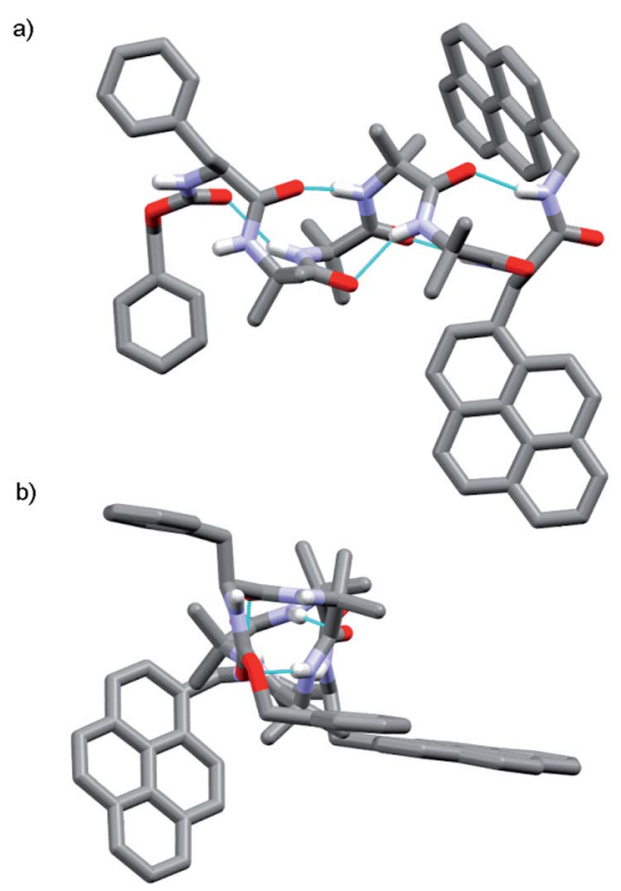

Fig. 2 X-ray crystal structure of $\mathrm{Cbz}(\mathrm{L}-\mathrm{Phe}) \mathrm{Aib}_{4}(\mathrm{~L}-\mathrm{Pya}) \mathrm{NHCH}_{2} \mathrm{Pyr} 13$, which adopts a right-handed $(P) 3_{10}$-helix. (a) Viewed side-on; (b) view down helix axis. 
a)<smiles>N[C@@H](C(=O)OCCBr)C(O)C(=O)OCCBr</smiles>
b)<smiles>[R]OC(=O)[C@@H](N)[C@@H](O)C(=O)O[R]</smiles>
i $\quad 16, \mathrm{R}=\mathrm{Me}(53 \%)$

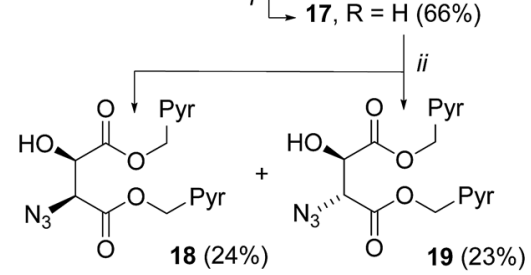

c)

$$
\begin{aligned}
& \mathrm{Cbz}(\mathrm{L}-\mathrm{Phe}) \mathrm{Aib}_{4} \mathrm{OH} 7 \stackrel{\mathrm{iii} \text {, then } 18 \text { and } i v}{\longrightarrow} 20(15 \%) \\
& \mathrm{Cbz}(\mathrm{D}-\mathrm{Phe}) \mathrm{Aib}_{4} \mathrm{OH} \mathbf{8} \stackrel{i i i \text {, then } 18 \text { and } i v}{\longrightarrow} \mathbf{2 1}(16 \%) \\
& \mathrm{Cbz}(\mathrm{L}-\mathrm{Phe}) \mathrm{Aib}_{4} \mathrm{OH} 7 \stackrel{\mathrm{iii} \text {, then } 19 \text { and } i v}{\longrightarrow} 22(12 \%) \\
& \mathrm{Cbz}(\mathrm{D}-\mathrm{Phe}) \mathrm{Aib}_{4} \mathrm{OH} 8 \stackrel{i i i \text {, then } 19 \text { and } i v}{\longrightarrow} 23(16 \%)
\end{aligned}
$$

Scheme 2 (a) Example of a bis(pyrene) aminoalcohol probe for attachment to the C-terminus of foldamers; (b) synthesis of 'second generation' probes 18-19. Pyr = pyren-1-yl. (i), Lil, THF reflux, $48 \mathrm{~h}$ then $1 \mathrm{M} \mathrm{HCl}$. (ii), 1-(Bromomethyl)pyrene, $\mathrm{Et}_{3} \mathrm{~N}, \mathrm{MeCN}$, reflux, $72 \mathrm{~h}$; (c) coupling to foldamers 7 and 8 , (iii), EDC, HOBt, THF, RT, 30 min. (iv), $\mathrm{PEt}_{3}, \mathrm{THF}, \mathrm{RT}, 16 \mathrm{~h}$.

changes in a perhydroanthracene ring. ${ }^{22}$ Furthermore, earlier work in our group ${ }^{6 a, c}$ had indicated that a hydroxylated Cterminus forms a favorable hydrogen bond with the terminal hydrogen-bond acceptors of the 310 -helix. The consequent reduction in conformational freedom allowed a detectable response to changes in screw-sense preference in an analogous NMR spectroscopic probe.

Diester 16 was synthesized from L-tartrate by the method of Breuning et al., ${ }^{23}$ hydrolyzed, and alkylated by heating to reflux with bromomethylpyrene and triethylamine in dry acetonitrile for $72 \mathrm{~h} .{ }^{1} \mathrm{H}$ NMR spectroscopy of the crude product mixture indicated epimerization to a 1.2 : 1 mixture of the diastereoisomeric azides 18 and 19. These diastereoisomers were separated by chromatography, and one-pot Staudinger-Vilarrasa coupling of either 18 or 19 to either 7 or 8 yielded sufficient amounts of pure foldamers 20-23 for fluorimetric studies (Scheme 2).

Strong excimer emission in the fluorescence spectra of 20-23 indicates that the pyrene groups are in close proximity. However, there were only small differences in the $E / M$ ratio between foldamers with either a $\mathrm{Cbz}(\mathrm{D}-\mathrm{Phe})$ or a $\mathrm{Cbz}(\mathrm{L}-\mathrm{Ph}$ ) $\mathrm{N}$ terminal controller. The ${ }^{1} \mathrm{H}$ NMR spectra of peptides 20-23 in $\mathrm{CDCl}_{3}$ solution revealed similar chemical shifts and coupling constants for the backbone $\alpha$-protons of the fluorophore unit, hinting that the C-terminal reporter group adopts a similar conformation in all cases (see the ESI $\dagger$ ). In contrast, the differences between the resonances of the $\mathrm{Cbz}(\mathrm{D}-\mathrm{Phe})$ and $\mathrm{Cbz}(\mathrm{L}$-Phe) residues the $\mathrm{N}$-terminus are more noticeable, suggesting that, like the first generation probes, these 1,2aminoalcohol-based reporter groups exert too much control over helical screw-sense.

\section{Development of 1,2-diamine-based probes}

A final 'third generation' of bis(pyrene)-containing probes (Fig. 1e and Scheme 3a and b) was designed based around a chiral, 1,2-disubstituted ethylenediamine unit. In diamine 27, the two pyrene systems are closer than in the previous probe structures. Diamine 28, with longer, rigid phenolic arms, was made in the expectation that torsional changes around the central $\mathrm{C}-\mathrm{C}$ bond would be amplified into more significant changes in the relative positions of the pyrene fluorophores.

The diamines were made using the method of Chin and coworkers. $^{24}$ 1-Pyrenylaldehyde 24 was mixed with $(1 R, 2 R)-1,2$ bis(2'-hydroxyphenyl)ethylenediamine 26 in DMSO. After $3 \mathrm{~h}$ the solution was poured into water to precipitate the crude diimine. After re-dissolution in THF and reaction with $\mathrm{HCl}$, analytically pure $(1 S, 2 S)$-1,2-bis(1'-pyrene)ethylenediamine dihydrochloride 27 was obtained. Similarly, 4-(pyren-1'-ylmethoxy)benzaldehyde 25 was treated with 26 using an identical method to give $(1 S, 2 S)$-1,2-bis(4'-(pyren-1-ylmethoxy)phenyl) ethane-1,2-diamine dihydrochloride 28 (Scheme 3a).

These diamine probes were coupled to the enantiomeric pair of CbzPhe capped Aib tetramers 7 and 8 to give foldamers 29-32 (Scheme 3b). Encouragingly all four foldamers showed high levels of excimer emission. However, dilution studies of 31 (10 $\mu \mathrm{M}$ to $1.25 \mu \mathrm{M}$ ) showed that excimer emission from this long ( $S, S$-BisPhenPyrEt) $\mathrm{NH}_{2}$ reporter had a significant component arising from intermolecular interactions, even in methanol (Fig. 3a). In contrast, dilution studies on 29 and 30, which have foldamers ligated to the shorter diamine probe 27 , showed a smaller contribution to the excimer emission from intermolecular interactions (Fig. 3b-d). Most importantly, the

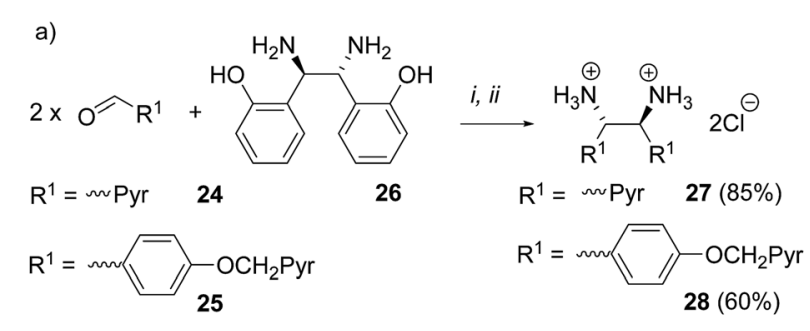

b)

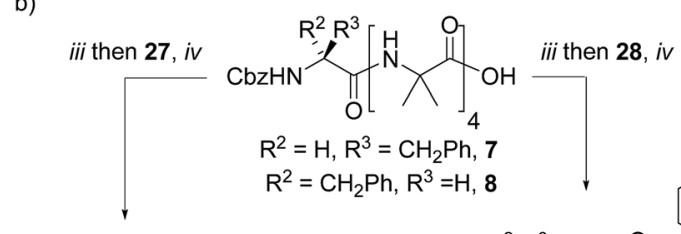

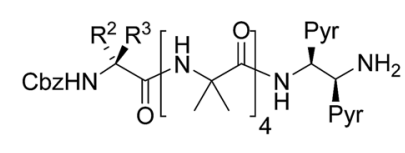

(S,S-BisPyrEt) $\mathrm{NH}_{2}$ reporter

$\mathrm{R}^{2}=\mathrm{H}, \mathrm{R}^{3}=\mathrm{CH}_{2} \mathrm{Ph}, 29(88 \%)$

$\mathrm{R}^{2}=\mathrm{CH}_{2} \mathrm{Ph}, \mathrm{R}^{3}=\mathrm{H}, 30(74 \%)$

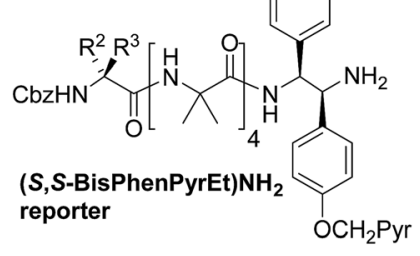

$\mathrm{R}^{2}=\mathrm{H}, \mathrm{R}^{3}=\mathrm{CH}_{2} \mathrm{Ph}, 31(56 \%)$ $\mathrm{R}^{2}=\mathrm{CH}_{2} \mathrm{Ph}, \mathrm{R}^{3}=\mathrm{H}, 32(41 \%)$
Scheme 3 (a) Synthesis of 'third generation' probes 27 and 28. Pyr = pyren-1-yl. (i), DMSO, 3 h. then $\mathrm{H}_{2} \mathrm{O}$. (ii) THF, Conc. $\mathrm{HCl}$; (b) synthesis of foldamers 29-32 bearing third generation probes. (iii), HOBt, $\mathrm{EDC} \cdot \mathrm{HCl}, \mathrm{CH}_{2} \mathrm{Cl}_{2}$. (iv), i- $\mathrm{Pr}_{2} \mathrm{NEt}, \mathrm{RT}, 2 \mathrm{~d}$. 

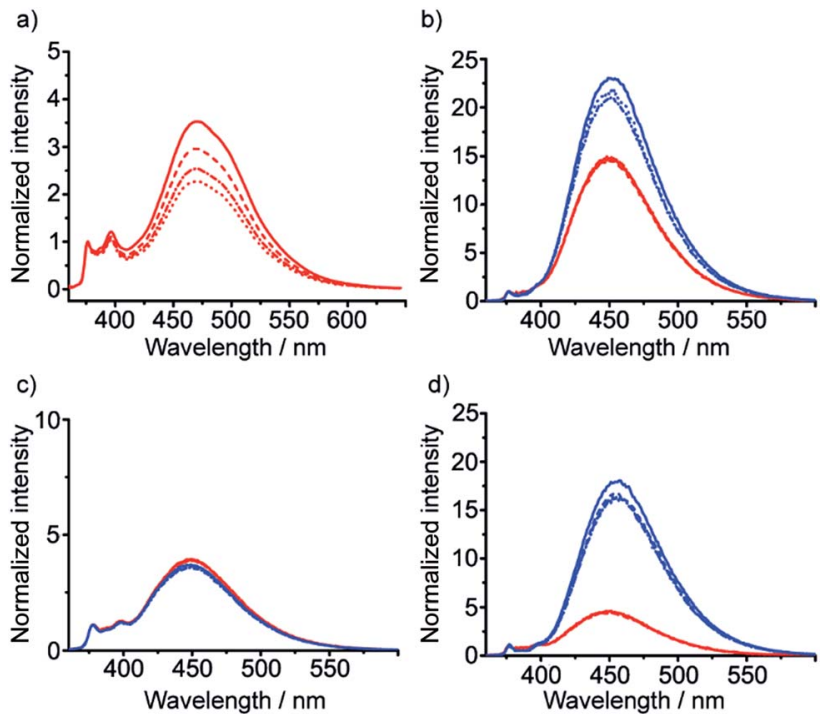

Fig. 3 Emission spectra normalized to 1 at $377 \mathrm{~nm}$ from (a) $31 \mathrm{in}$ $\mathrm{MeOH}$; (b) 29 ( $M$ helix, red traces) and 30 ( $P$ helix, blue traces) in $\mathrm{MeOH}$; (c) 29 (red traces) and 30 (blue traces) in $\mathrm{CH}_{2} \mathrm{Cl}_{2}$; (d) 29 (red traces) and 30 (blue traces) in MeCN. Foldamer concentrations: $10 \mu \mathrm{M}$ (solid line) $5 \mu \mathrm{M}$ (dashed line) $2.5 \mu \mathrm{M}$ (dash-dotted line) and $1.25 \mu \mathrm{M}$ (dotted line).

diastereoisomeric pairs of foldamers showed significant, measurable differences in $E / M$ ratio in $\mathrm{CH}_{3} \mathrm{CN}$ and $\mathrm{CH}_{3} \mathrm{OH}$, if not $\mathrm{CH}_{2} \mathrm{Cl}_{2}$ (Fig. 3b-d). Further studies were therefore performed on foldamers incorporating the diamine probe 27 . The resulting C-terminal reporter group, denoted as ( $S, S$-BisPyrEt) $\mathrm{NH}_{2}$, had the best performance of the reporters tested by that point.

\section{Optimization of 1,2-diamine-based probes}

The performance of the $(S, S$-BisPyrEt $) \mathrm{NH}_{2}$ conformational reporter derived from third generation probe 27 was characterized as a function of screw-sense control from the $\mathrm{N}$ terminus. To do this, additional foldamers with an $\mathrm{N}$-terminal $\mathrm{Cbz}(\alpha-\mathrm{MeVal})$ residue were synthesized: the ability of these $\mathrm{N}$ terminal residues to induce a preferred screw-sense in an Aib foldamer is known to be relatively solvent-independent. ${ }^{5}$ Either $\mathrm{L}^{-}$or $\mathrm{D}-\mathrm{Cbz}(\alpha \mathrm{MeVal}) \mathrm{Aib}_{4} \mathrm{OH}$ were coupled to probe 27 to give the diastereoisomers 35 and 36 (Scheme 4). ${ }^{5}$

It was also hoped that C-terminal acetylation would optimize the performance of this reporter group, as the acetamide produced might promote hydrogen bonding from the C-terminal $\mathrm{N}-\mathrm{H}$ back into the $3{ }_{10}$-helix. Therefore both 35 and 36 were acetylated to give the diastereoisomeric foldamer pair 37 and 38, each of which bear a modified C-terminal reporter, denoted as $\left(S, S\right.$-BisPyrEt)NHAc. This acetylation of the $(S, S$-BisPyrEt $) \mathrm{NH}_{2}$ reporter to produce the $(S, S$-BisPyrEt)NHAc reporter resulted in a clear increase in performance (Fig. 4).

Dividing the $E / M$ ratio of the fluorescent reporter in a $P$ helical environment by the $E / M$ ratio of the same reporter in an $M$ helical environment gives a sensitivity ratio $\left(S_{\mathrm{R}}=(E / M\right.$ for $P$-helix $) /(E / M$ for $M$-helix $))$ that provides a measure of the probe's ability to report on conformational change: the greater the

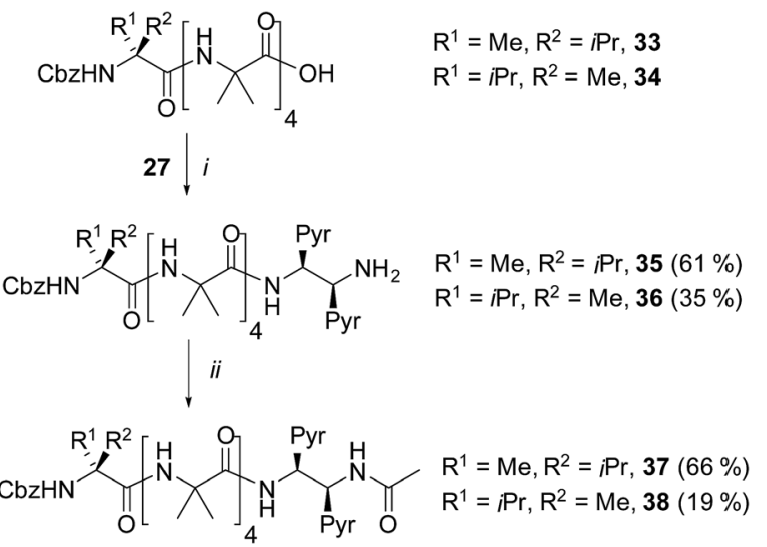

Scheme 4 Synthesis of $\alpha$-MeVal controlled foldamers 35-38. (i), EDC/ $\mathrm{HOBt}$, i- $\mathrm{Pr}_{2} \mathrm{NEt}, \mathrm{CH}_{2} \mathrm{Cl}_{2}$; (ii), $\mathrm{Ac}_{2} \mathrm{O}, \mathrm{CH}_{2} \mathrm{Cl}_{2}$.

deviation from 1, the greater the sensitivity. The amineterminated reporter $\left(S, S\right.$-BisPyrEt) $\mathrm{NH}_{2}$ in 35 and 36 had $S_{\mathrm{R}}$ values close to 1 in the four different solvents tested (Fig. 4c). The results for the acetamide-terminated reporter $(S, S$-BisPyrEt)NHAc in 37 and 38 highlighted its superiority. In polar solvents the $E / M$ ratio for the $P$ helix was three times that of the $M$ helix. Even in $\mathrm{CH}_{2} \mathrm{Cl}_{2}$, where the amine-terminated reporter in 35 and 36 was insensitive to different conformations, the $E / M$ ratio for the $P$ helix was found to be 6.4 times that of the $M$ (Fig. $4 \mathrm{~d}$ ).

It was expected that the chiral acetylated reporter $(S, S$-BisPyrEt)NHAc may itself induce some degree of screw-sense control, but the extent of this conformational influence in

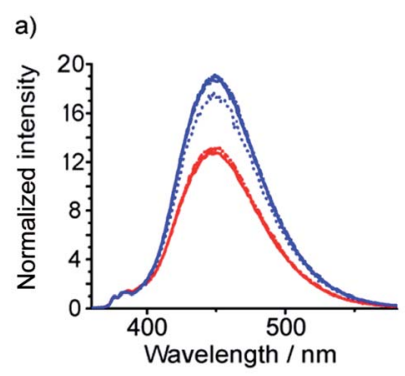

c)

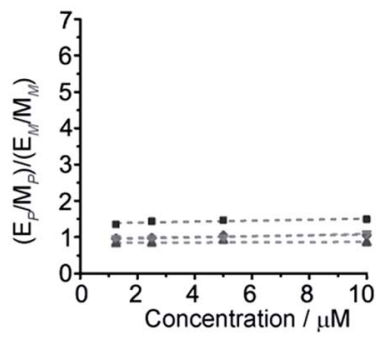

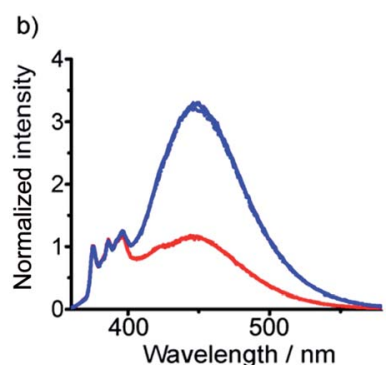

d)

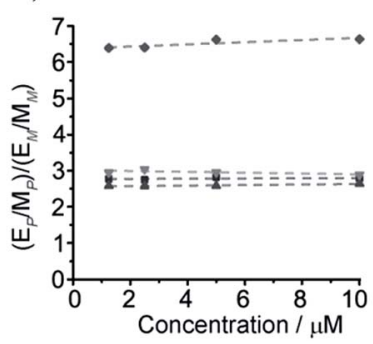

Fig. 4 (a, b) Fluorescence emission spectra (normalized to 1 at 377 $\mathrm{nm}$ ) in $\mathrm{MeOH}$ of (a) amino-terminated foldamers 35 ( $P$ helix, blue trace) and 36 ( $M$ helix, red trace); (b) acetamide-terminated foldamers 37 (blue) and 38 (red) in $\mathrm{MeOH}$. Spectra shown for $10 \mu \mathrm{M}$ (solid line) 5 $\mu \mathrm{M}$ (dashed line) $2.5 \mu \mathrm{M}$ (dash-dotted line) and $1.25 \mu \mathrm{M}$ (dotted line) of compound; $(c, d)$ sensitivity ratio $\left(S_{R}\right)$ values for (c) 35 and 36; (d) 37 and 38. $S_{R}=([E / M$ for $P] /[E / M$ for $M])$ for the diastereomeric pairs in $\mathrm{CH}_{2} \mathrm{Cl}_{2}$ $(\diamond) \mathrm{MeOH}(\boldsymbol{\nabla}) \mathrm{MeCN}(\boldsymbol{\Delta})$ and THF ( $\nabla$ ) at different concentrations. For 35 and 36 the response in $\mathrm{CH}_{2} \mathrm{Cl}_{2}$ is identical to that in THF. 
solution was unknown. Foldamers $\mathbf{4 0}$ and $\mathbf{4 1}$ (Scheme 5a) were thus used to measure the screw-sense preference exerted by $(S, S$-BisPyrEt $) \mathrm{NH}_{2}$ and $(S, S$-BisPyrEt $) \mathrm{NHAc}$. The $\mathrm{N}$-terminal CbzGly residue in these compounds acts an NMR reporter of induced screw-sense preference; the fast-exchange chemical shift separation of the $\mathrm{AB}$ system arising from the diastereotopic methylene protons of the Gly residue is proportional to the screw-sense preference (defined by the helical excess, h.e. $=$ $([P$-foldamer $]-[M$-foldamer $]) /[$ total foldamer $])$ induced in the helical chain by the chiral C-terminal probe. ${ }^{1 d}$

Coupling 27 to $\mathrm{CbzGlyAib}_{4} \mathrm{OH} 39$ gave $\mathrm{CbzGlyAib}_{4}(S, S$-BisPyrEt) $\mathrm{NH}_{2} \mathbf{4 0}$, which was acetylated to give $\mathrm{GlyAib}_{4}(S, S$-BisPyrEt $)$ NHAc 41. The glycine residue of amine-terminated foldamer $\mathbf{4 0}$ appears as an $\mathrm{AB}$ system with significant anisochronicity $(\Delta \delta=$ $130 \mathrm{ppb}$ ), indicating powerful induction of a screw-sense preference by the fluorescent reporter (Scheme 5b): this aminoterminated bis(pyrene) motif in $\mathbf{4 0}$ thus behaves as a controller rather than a reporter. In contrast, the $\mathrm{CH}_{2}$ group of the glycine residue in acetamide $\mathbf{4 1}$ appears as a $2 \mathrm{H}$ singlet with no detectable anisochronicity, confirming that this reporter exerts very little control over the screw-sense preference of the Aib helix (Scheme $5 \mathrm{c}$ ). Whether or not acetylation increases the strength of the C-terminal hydrogen bond, it certainly weakens the ability of the chiral ethylenediamine moiety to control helical screw-sense, while still retaining its ability to respond to its environment: in other words, acetylation successfully transforms the aminoterminated bis(pyrene) motif from a controller into a reporter.

\section{Structural characterization of C-terminal acetylated 1,2- diamine-based probes}

To gain more insight into the molecular structure that links the conformation of the reporter group with the helical sense of the foldamer, five new foldamers terminated with acetylated 1,2diamine-based probes were synthesized. These compounds included those designed to provide enantiomeric pairs of a)<smiles>CC(NC(=O)C(C)NC(=O)[O-])C(=O)O</smiles><smiles>CC(C)(NC(=O)CNC(=O)C(Br)NC(=O)OCc1ccccc1)C(=O)NC(Br)C(N)Br</smiles><smiles></smiles>

$41,25 \%$

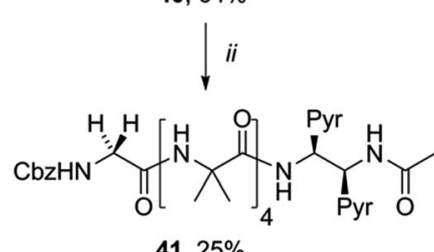

b)

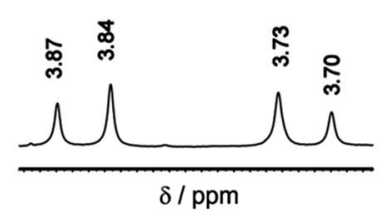

Scheme 5 (a) Synthesis of 40 and 41. (i), EDC/HOBt, i- $\mathrm{Pr}_{2} \mathrm{NEt}, \mathrm{CH}_{2} \mathrm{Cl}_{2}$ (ii), $\mathrm{Ac}_{2} \mathrm{O}, \mathrm{CH}_{2} \mathrm{Cl}_{2}$. (b) Appearance of the ${ }^{1} \mathrm{H}$ NMR resonances in $\mathrm{CD}_{3} \mathrm{OD}$ of the Gly $\mathrm{CH}_{2}$ of (b) 40 and (c) 41 . selected foldamers. They included compounds with no chiral controller at the N-terminus (43 and 47), as well as those with quaternary amino acids at the $\mathrm{N}$-terminus (49, the enantiomer of 38 , Scheme 6).

To create enantiomers of $\mathbf{3 8}$ and $\mathbf{4 3}$, the $R, R$ stereoisomer of the (BisPyrEt)NHAc probe was synthesized. It was straightforwardly available from (1S,2S)-1,2-bis(2'-hydroxyphenyl)ethylenediamine 45, the commercially available enantiomer of $\mathbf{2 6}$. The resulting $R, R$-bis(pyrene) probe $\mathbf{4 6}$ was then coupled both to uncontrolled Aib tetramer 42, Cbz(D-Phe) controlled Aib tetramer 8, and $\mathrm{Cbz}(\mathrm{L}-\alpha \mathrm{MeVal})$ controlled Aib tetramer 33. The resulting foldamers 47-49 each bear the ( $R, R$-BisPyrEt)NHAc reporter.

Of these five compounds, foldamers 43,48 and 49 were able to be crystallized and their solid state structures were determined by X-ray crystallography.

The X-ray crystal structure of control compound $\mathrm{N}_{3} \mathrm{Aib}_{4}(S, S$ BisPyrEt)NHAc 43, which lacks a chiral N-terminal controller, suggests one reason why the acetylated reporter group is so sensitive to changes in helical conformation. Foldamer $\mathbf{4 3}$ (Fig. 5) adopts a left-handed $M$ helical conformation, necessarily as a result of the chiral influence of the $(S, S$-BisPyrEt $)$ NHAc probe. There is a bifurcated hydrogen bond between the carbonyl of the second Aib residue and both amide NHs of the ethylenediamine probe, coupling the torsion angle of the central $\mathrm{C}-\mathrm{C}$ bond in the fluorescent probe (PyrC-CPyr torsion angle $-169^{\circ}$ ) with the position of this carbonyl within the helical structure. The large separation of the pyrene groups, with an antiperiplanar relationship between $\mathrm{N}-\mathrm{C}$ (pyren-1-yl) bonds, results from significant steric interactions within the reporter group. The wide separation of the pyrene groups implies 43 should show a low $E / M$ ratio. However the net $E / M$ in solution (2.50 in $\mathrm{MeOH}$ ) also includes excimer contributions from the $P$ screw-sense conformation (which does not appear in

a)

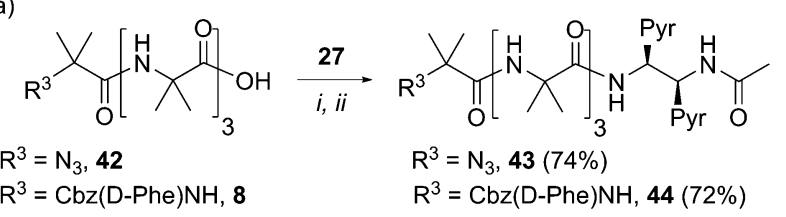

b)

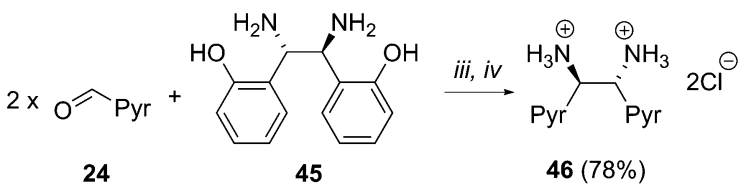

c)

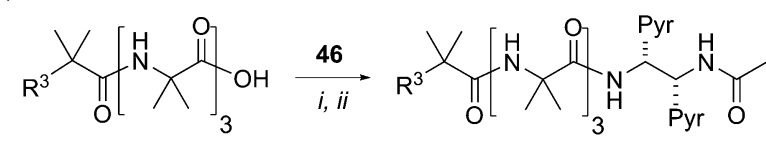

$\mathrm{R}^{3}=\mathrm{N}_{3}, \mathbf{4 2}$

$\mathrm{R}^{3}=\mathrm{Cbz}(\mathrm{D}-\mathrm{Phe}) \mathrm{NH}, \mathbf{8}$

$\mathrm{R}^{3}=\mathrm{Cbz}(\mathrm{L}-\alpha \mathrm{MeVal}) \mathrm{NH}, \mathbf{3 3}$

$R^{3}=N_{3}, 47(68 \%)$

$\mathrm{R}^{3}=\mathrm{Cbz}(\mathrm{D}-\mathrm{Phe}) \mathrm{NH}, \mathbf{4 8}(43 \%)$

$\mathrm{R}^{3}=\mathrm{Cbz}(\mathrm{L}-\alpha \mathrm{MeVal}) \mathrm{NH}, 49(24 \%)$

Scheme 6 Synthesis of uncontrolled foldamers 43 and 47, D-Phe controlled foldamers 44 and 48 , and $L-\alpha-M e V a l$ controlled foldamer 49. (a, c) (i), EDC/HOBt, i- $\mathrm{Pr}_{2} \mathrm{NEt}, \mathrm{CH}_{2} \mathrm{Cl}_{2}$; (ii), $\mathrm{Ac}_{2} \mathrm{O}, \mathrm{CH}_{2} \mathrm{Cl}_{2}$. (b) (iii), DMSO, $3 \mathrm{~h}$, then $\mathrm{H}_{2} \mathrm{O}$. (iv) $\mathrm{THF}$, conc. $\mathrm{HCl}$. 
a)

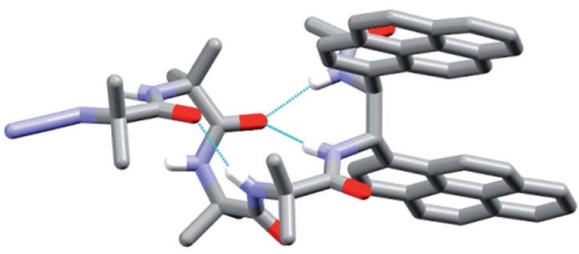

b)

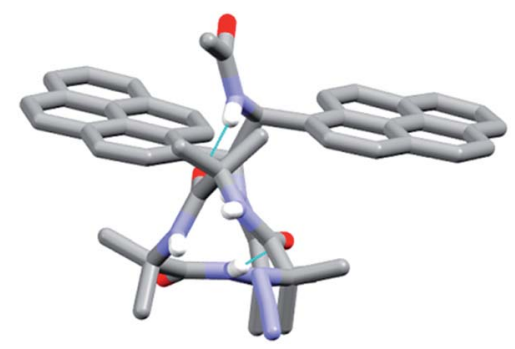

Fig. 5 X-ray crystal structure of 43 (a) viewed side-on, showing $M$ helical structure with bifurcated $\mathrm{NH}$ bond between the carbonyl of Aib-2 and the amide NHs of the probe; (b) viewed along the helix axis from $\mathrm{N}$ - to $\mathrm{C}$-terminus, revealing the large separation of the pyrene groups.

the solid state structure), in which the pyrene groups may lie much closer together.

The structure of $\mathbf{4 3}$ in the solid state shows that the $(S, S$ BisPyrEt)NHAc reporter will favor a $M$ helical conformation and the enantiomeric $(R, R$-BisPyrEt)NHAc reporter will favor a $P$ helical conformation, although studies on $\mathbf{4 1}$ in solution show that the inductive strength of the reporter is low. A chiral influence from the $\mathrm{N}$-terminus could enhance or counteract the conformational preference of the reporter. For example, both $\mathrm{Cbz}(\mathrm{L}-\alpha \mathrm{MeVal})$ and $\mathrm{Cbz}(\mathrm{D}-\mathrm{Phe})$ residues favor adoption of a $P$ $3_{10}$-helix through the formation of either an N-terminal type III or a type II' $\beta$-turn respectively., ${ }^{5,21}$ Therefore, if combined with the $(R, R$-BisPyrEt)NHAc reporter, both the $\mathrm{N}$ - and $\mathrm{C}$-terminal screw-sense preferences (for a $P 3_{10}$-helix) would be "matched".

The X-ray crystal structure of $\mathbf{4 9}$ (the enantiomer of 38) shows "matching" of screw-sense preferences. The foldamer adopts a $3{ }_{10}$-helix with a $P$ screw-sense (Fig. 6), which is the screw-sense favored both by $\mathrm{Cbz}(\mathrm{L}-\alpha \mathrm{MeVal})$ at the $\mathrm{N}$-terminus, and (given the structure of 43) by the (R,R-BisPyrEt)NHAc reporter. There are only $P$ helices in the unit cell of $\mathbf{4 9}$, and each foldamer adopts a type III $\beta$-turn at the $\mathrm{N}$-terminus with a bifurcated hydrogen bond to the two amide NHs of the ethylenediamine at the Cterminus (as observed in the structure of 43). The good helical control exerted by $\alpha \mathrm{MeVal}$ and large separation of the antiperiplanar pyrene groups (PyrC-CPyr torsion angle $+170^{\circ}$ ) is consistent with the low excimer emission for both $\mathbf{4 9}$ and 38 in organic solvents.

Foldamer 48 also has "matched" screw-sense preferences, with the D-Phe controller expected to induce a $P$ screw-sense. However the X-ray crystal structure of $\mathbf{4 8}$ is a remarkable example of where both $P$ and $M$ screw-senses occur in the unit cell (Fig. 7). Indeed previous studies have shown that Aib tetramers containing $\mathrm{N}$-terminal tertiary amino acids display less uniform structures in the solid state, and can in some case

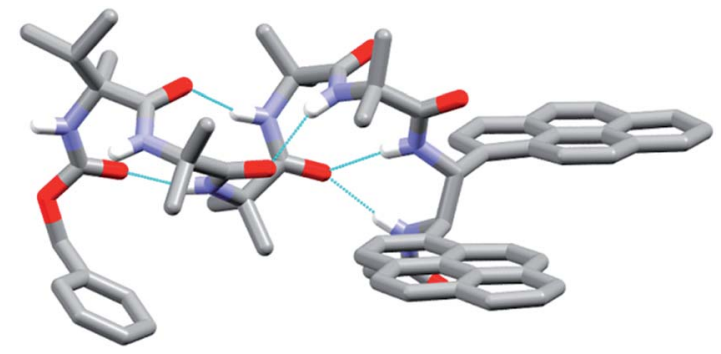

Fig. 6 X-ray crystal structure for 49 . Viewed side-on, showing $P$ helical structure with bifurcated $\mathrm{NH}$ bond between the carbonyl of Aib-2 and amide NHs of the probe.

even adopt the opposite helical sense in the solid state compared to that found in solution. ${ }^{5}$ The conformer with the $P$ screw-sense has a structure around the bis(pyrene) probe that is analogous to that observed for $\mathbf{4 3}$ and $\mathbf{4 9}$, with spatially wellseparated pyrene groups (PyrC-CPyr torsion angle $+167^{\circ}$ ) and a bifurcated hydrogen bond to the amides of the C-terminal reporter. At the $\mathrm{N}$-terminus, the chiral $\mathrm{D}$-Phe residue induces a type II' $\beta$-turn, similar to that observed for other Aib foldamers capped by tertiary amino acids..$^{5,21}$

In contrast, the conformer with the $M$ screw-sense has the pyrene groups of the reporter lying on top of one another in a "V"-shaped geometry, suggesting that $M 3_{10}$-helices terminated with $\left(R, R\right.$-BisPyrEt)NHAc or $P 3_{10}$-helices terminated with $(S, S$-BisPyrEt)NHAc would show strong excimer emission. This change in the torsion angle in the reporter to $+69^{\circ}$ is

a)

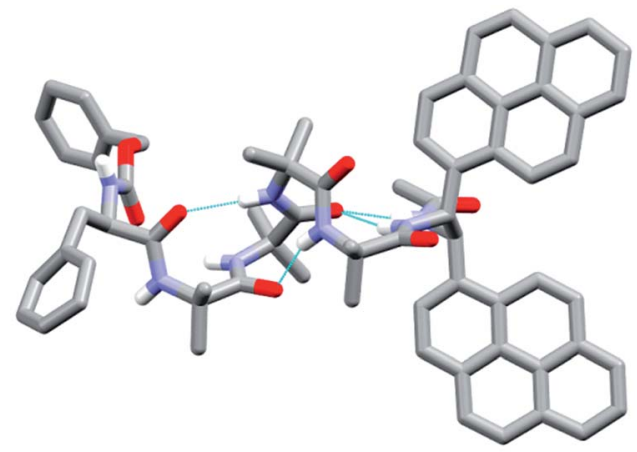

b)

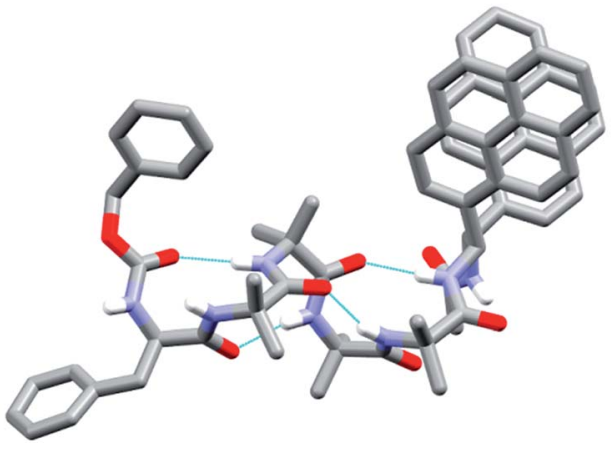

Fig. 7 X-ray crystal structure for 48 , showing the two conformers observed in the unit cell. (a) Top view of $P$ helical conformer (b) top view of $M$ helical conformer. 
accompanied by the loss of the hydrogen bond from the carbonyl of the second Aib to the NH of the C-terminal acetamide. At the N-terminus, the chiral $\mathrm{D}$-Phe residue now adopts a type III $\beta$-turn, similar to that induced by the ${ }_{\mathrm{L}}-\alpha \mathrm{MeVal}$ in $\mathbf{4 9}$ but with the opposite sense.

\section{Applications of 1,2-diamine-based probes: ( $S, S$-BisPyrEt)NHAc as a reporter of conformation in organic solvents}

Our next task was to correlate the $E / M$ response of one of these optimized bis(pyrene) probes, specifically ( $S, S$-BisPyrEt)NHAc, with the quantified screw-sense preference of the adjacent helix. Two further foldamers $\mathbf{5 2}$ and $\mathbf{5 3}$ with almost quantitative screw-sense preference were synthesized (Scheme 7). Nterminal $\mathrm{Cbz}(\alpha \mathrm{MeVal})_{2}$ controllers induce very high levels of control over the screw-sense of Aib foldamers (almost 100\%, especially in non-polar solvents). ${ }^{\mathbf{1}, 5}$ Diamine 27 was ligated to 50 and 51, then acetylated to give $P$ helical 52 and $M$ helical 53.

The screw-sense preference of these controllers ranges from $\sim 100 \% M$ to $\sim 100 \% P$, therefore covering the entire $E / M$ response range for the acetamide probe (Table 1). These data show that, as expected from the structures of 43,48 and 49 (as well as the structure of $\mathbf{5 3}$, see the ESI $\dagger$ ) increasing $M$ screw-sense reduces excimer fluorescence from the $(S, S$-BisPyrEt)NHAc reporter, consistent with an increase in the population of conformers with widely separated pyrene groups. The response is stronger in methanol than acetonitrile, although the trends are similar (see the ESI $\dagger$ ). These data could be fitted to a simple model that assumes only two conformational populations, namely $M$ and $P 3_{10}$-helices (see the ESI $\dagger$ ). This model gave good agreement with the experimental values and gave calculated $E / M$ values of 1.05 for the $M$ helical conformer, 5.50 for the $P$ helical conformer and 2.50 for the racemic mixture.

\section{Applications of 1,2-diamine-based probes: ( $S, S$-BisPyrEt)NHAc as a reporter of conformation in the membrane phase}

Isotropic organic solvent is often used as a model system for phospholipid bilayers, with the water/bilayer interface modelled by methanol/water mixtures and the center of the bilayer modeled with low polarity solvents such as chloroform. ${ }^{25}$ The development of hydrophobic foldamers bearing bis(pyrene) reporter groups offers a valuable opportunity to ascertain the extent to which organic solvent is a useful model for bilayers
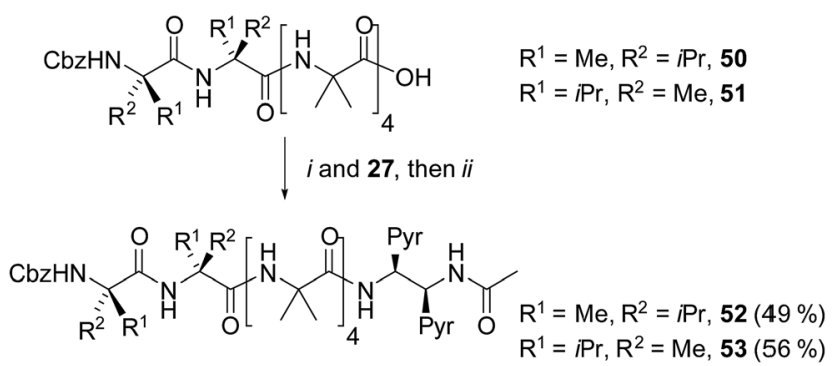

Scheme 7 Synthesis of $(\alpha \mathrm{MeVal})_{2}$ controlled foldamers 52 and 53. (i), $\mathrm{EDC} / \mathrm{HOBt}$, i- $\mathrm{Pr}_{2} \mathrm{NEt}, \mathrm{CH}_{2} \mathrm{Cl}_{2}$; (ii), $\mathrm{Ac}_{2} \mathrm{O}, \mathrm{CH}_{2} \mathrm{Cl}_{2}$.
Table $1 E / M$ values and reported induced screw-sense preferences for foldamers 37, 38, 41, 43, 44, 52 and 53

\begin{tabular}{llll}
$\begin{array}{l}\text { Compound, } \\
\text { [controller] }\end{array}$ & $\Delta \delta^{a}$ & h.e. & \\
\hline $\mathbf{5 3},\left[\mathrm{Cbz}(\mathrm{D}-\alpha \mathrm{MeVal})_{2}\right]$ & 383 & -95 & E/M \\
$\mathbf{3 8},[\mathrm{Cbz}(\mathrm{D}-\alpha \mathrm{MeVal})]$ & 275 & -68 & 1.12 \\
$\mathbf{4 1},[\mathrm{Cbz}(\mathrm{Gly})]$ & 0 & 0 & 1.38 \\
$\mathbf{4 3},\left[\mathrm{N}_{3}\right]$ & 0 & 0 & 2.47 \\
$\mathbf{4 4},[\mathrm{Cbz}(\mathrm{D}-\mathrm{Phe})]$ & 209 & +52 & 2.50 \\
$\mathbf{3 7},[\mathrm{Cbz}(\mathrm{L}-\alpha \mathrm{MeVal})]$ & 275 & +68 & 3.32 \\
$\mathbf{5 2},\left[\mathrm{Cbz}(\mathrm{L}-\alpha \mathrm{MeVal})_{2}\right]$ & 383 & +95 & 3.81 \\
\end{tabular}

${ }^{a}$ Anisochronicity $(\Delta \delta)$ induced by each controller in $\mathrm{Aib}_{4}$ foldamers, determined using a C-terminal glycinamide reporter. ${ }^{5}$ ${ }^{b}$ Corresponding helical excess (h.e.). ${ }^{c} E / M$ ratio measured in $\mathrm{MeOH}$ at $10 \mu \mathrm{M}$ using the $(S, S$-BisPyrEt $)$ NHAc reporter; monomer emission at $377 \mathrm{~nm}$, excimer is the maximum emission intensity from 410 to $600 \mathrm{~nm}$.

and to uncover how the membrane environment may exert a distinctive influence on the conformation of embedded compounds, like peptides and foldamers.

To verify that these foldamers would indeed successfully embed in vesicle membranes, giant unilamellar vesicles (GUVs) were prepared by electroformation from egg yolk phosphatidylcholine (EYPC) mixed with either 37 or 38 (1 mol\%). Fluorescence microscopy images showed bright excimer fluorescence from the membranes of the GUVs, with no visible fluorescence from any foldamer that might not have been incorporated into the bilayer (Fig. 8a). Furthermore, the uniform excimer fluorescence of $\mathbf{3 7}$ and 38 suggested the foldamers are evenly dispersed across the vesicle membrane, without visible microdomain formation; microdomains that are enriched in foldamer may produce intermolecular excimers. ${ }^{26}$ To confirm that intermolecular excimer emission is low, a membrane dilution experiment was performed. Foldamer $\mathbf{4 3}$ was embedded in the membranes of EYPC large unilamellar vesicles (LUVs, $800 \mathrm{~nm}$ diameter) at loadings of 0.2, 0.4, 0.6 and $1 \mathrm{~mol} \%$. Any non-embedded foldamer was removed by gel permeation chromatography (GPC) of the vesicular suspensions. The fluorescence spectra of each LUV suspension showed similar $E / M$ ratios $(E / M$ values of $1.07,1.02,1.01$ and 1.10 respectively), with no increase in $E / M$ as the loading increased (see the ESI $\dagger$ ). This mirrors observations for other Aib foldamers in EYPC LUVs, ${ }^{12}$ and suggests that the excimer emission observed is predominantly intramolecular in origin.

To measure how controllers of opposite chirality affect the conformation of foldamers in the membrane phase, $(S, S$-BisPyrEt) $\mathrm{NH}_{2}$-terminated foldamers 29, 30, 35 and 36 and $(S, S$ BisPyrEt)NHAc-terminated foldamers 37 and $\mathbf{3 8}$ (Schemes 3 and 4) were embedded in the membranes of EYPC LUVs at $1 \mathrm{~mol} \%$.

The fluorescence spectra of these vesicular suspensions are shown in Fig. 8b-d. As in organic solvent, the diastereoisomeric pairs of compounds showed distinguishably different fluorescence spectra, indicating that the fluorescent reporter was sensitive to conformational environment even in the phospholipid membrane phase. Some differences were however apparent on comparison with their emission spectra in organic 
a)

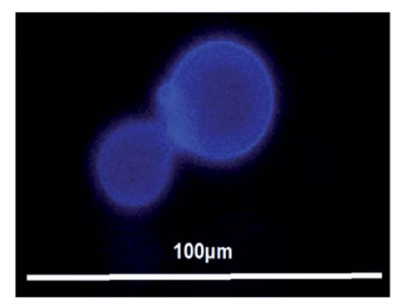

c) 35 in EYPC bilayers, $P$ helix

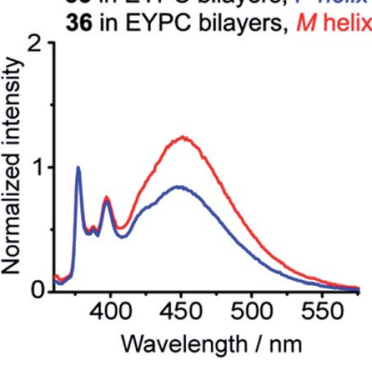

b) 29 in EYPC bilayers, $M$ helix

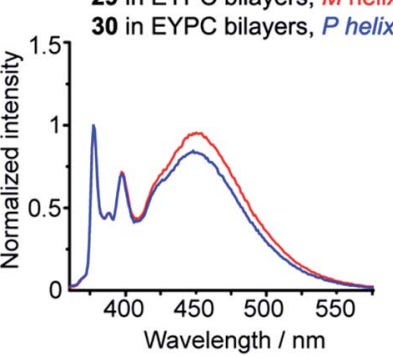

d) 37 in EYPC bilayers, $P$ helix

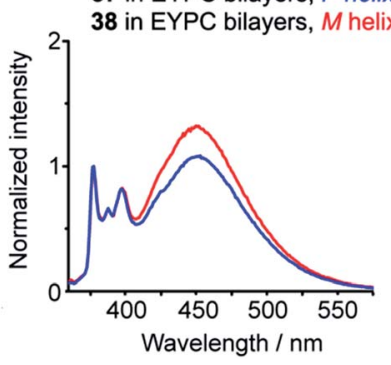

Fig. 8 (a) Epi-fluorescence microscopy image of EYPC GUVs with 37 embedded in the bilayers at $1 \mathrm{~mol} \%$; $(b-d)$ normalized fluorescence emission spectra for 29, 30, 35-38 (10 $\mu \mathrm{M}$, in EYPC LUVs, $800 \mathrm{~nm}$ diameter at $1 \mathrm{~mol} \%$, emission normalized to $377 \mathrm{~nm}$ ).

solvents. There was a significant reduction in $E / M$ values for all foldamers. All values were closer to 1 and the largest observed $E / M$ in bilayers was 1.47 , measured for the $(S, S$-BisPyrEt $) \mathrm{NH}_{2}-$ terminated foldamer with $\mathrm{Cbz}(\mathrm{D}-\alpha \mathrm{MeVal})$ controller (36). These data suggest that conformations with the pyrene groups in close proximity became less favorable. In addition, intriguingly, the helical screw-sense that showed the higher $E / M$ ratio was now reversed, with $M$ helices resulting in greater excimer emission. This change is ascribed to perturbation of the response from the reporter rather than a change in the screw-sense of the foldamer. ${ }^{27}$ The sensitivity ratio for foldamers $29,30,35-38$ in bilayers was therefore below 1. Inversion of the $S_{\mathrm{R}}$ value for $(S, S$-BisPyrEt)NHAc-terminated foldamers $\mathbf{3 7}$ and $\mathbf{3 8}$ in bilayers $\left(1 / S_{\mathrm{R}}=1.3\right)$ allows meaningful comparison to the $S_{\mathrm{R}}$ values for 37 and 38 in organic solution $\left(S_{\mathrm{R}}=2.7\right)$ and reveals a reduced sensitivity to conformational change when in bilayers. However the $\left(S, S\right.$-BisPyrEt) $\mathrm{NH}_{2}$-terminated foldamers $\mathbf{3 5}$ and $\mathbf{3 6}$ did not show a decrease in sensitivity when in bilayers $\left(1 / S_{R}=1.5\right.$ in bilayers, $S_{\mathrm{R}}=1.4$ in solution).

Although the $\left(S, S\right.$-BisPyrEt) $\mathrm{NH}_{2}$ reporter gave a slightly better sensitivity ratio in bilayers compared to the ( $S, S$-BisPyrEt)NHAc reporter, the latter was more versatile. Foldamers bearing this reporter (such as $\mathbf{3 7}$ and 38) were found to degrade more slowly upon storage at $4{ }^{\circ} \mathrm{C}$ than the amine-terminated reporters. Additionally the amino-terminus of the $(S, S$-BisPyrEt $) \mathrm{NH}_{2}$ reporter could become protonated in buffered solution ( $\mathrm{pH}$ 7.4) and thereby produce unwanted intermolecular interactions in biological environments. The combination of good membrane insertion, stability and the clear dependence of fluorescence emission on the induced local conformational environment shows that $(S, S$-BisPyrEt)NHAc reporters are useful tools for the

study of conformational change in membrane-embedded peptides.

The observed differences in the $E / M$ values between diastereoisomeric foldamers in vesicles show that the conformational relay in the foldamers remains intact in bilayers. Additionally, these synthetic compounds, with only a few chiral centers, can be used to gain new insights into intermolecular interactions with the matrix lipids of the membrane. In particular, comparing $E / M$ values from enantiomeric foldamers could reveal the often overlooked influence of phospholipid chirality on the conformation of embedded peptides and proteins.

\section{Application of 1,2-diamine-based probes to assess chiral induction by phospholipids in the membrane phase}

Naturally occurring phospholipids, such as the phosphatidylcholines found in EYPC, have an $R$ configuration at the central carbon of the glycerol backbone. Although the effect of phospholipid chirality on enantioselective processes in bilayers has been sparsely investigated, phospholipid bilayers have been shown to exhibit differential recognition of enantiomers of amino acids, ${ }^{28}$ dipeptides ${ }^{29}$ and ibuprofen. ${ }^{30}$ The effect of a bilayer on enantioselective reactions at its surface is less clear. $^{31,32}$

Reports by Nakagawa and co-workers indicate that phospholipid chirality can influence the conformational equilibria of embedded molecules; helicenes that rapidly interconvert between $M$ and $P$ helical conformations were found to deracemize in phospholipid bilayers. ${ }^{33,34}$ Although there are no reports of the deracemization of achiral peptides in phospholipid bilayers, micelles composed of $\mathrm{N}$-dodecylproline were used to induce a h.e. of at least $33 \%$ in an achiral 310 -helical Aib octamer. $^{35}$ Recent vibrational circular dichroism studies of enantiomeric Aib foldamers embedded in phospholipid bilayers hinted that phospholipid chirality may produce diastereoisomeric conformations. ${ }^{27}$ Therefore the availability of two pairs of enantiomeric foldamers bearing bis(pyrene) reporters (38 and $49 ; 43$ and 47 ) offers a unique opportunity to observe chiral induction due to the phospholipids that constitute the bilayer.

The enantiomers of each pair gave the same fluorescence emission spectra in isotropic organic solvent (methanol), with higher excimer emission from the uncontrolled helices (Fig. 9a). However, at $1 \mathrm{~mol} \%$ in EYPC vesicles, significant differences in the ratiometric emission from enantiomeric foldamers $\mathbf{4 3}(E / M$ $=1.11 \pm 0.02)$ and $47(E / M=0.96 \pm 0.02)$ were observed across either four or three pairs (respectively) of separately prepared samples. Similarly, a difference was observed between enantiomers $38(E / M=1.37)$ and $49(E / M=1.62)$ (Fig. 9b).

The observation of a small but significant difference between the $E / M$ ratios for $\mathbf{4 3}$ and $\mathbf{4 7}$, with the $S, S$ enantiomer higher than the $R, R$ shows the chirality of the bilayer can perturb the response of the (BisPyrEt)NHAc reporter. Furthermore, the different $E / M$ values for $\mathbf{3 8}$ and $\mathbf{4 9}$ show bilayer chirality also affects the degree of induction from the controller, since for this pair the $R, R$ reporter gives a higher $E / M$ value than the $S, S$ reporter. The difference in $E / M$ between enantiomers 38 and $\mathbf{4 9}$ in a bilayer $(\Delta(E / M)=+0.25)$ is comparable to the difference in 


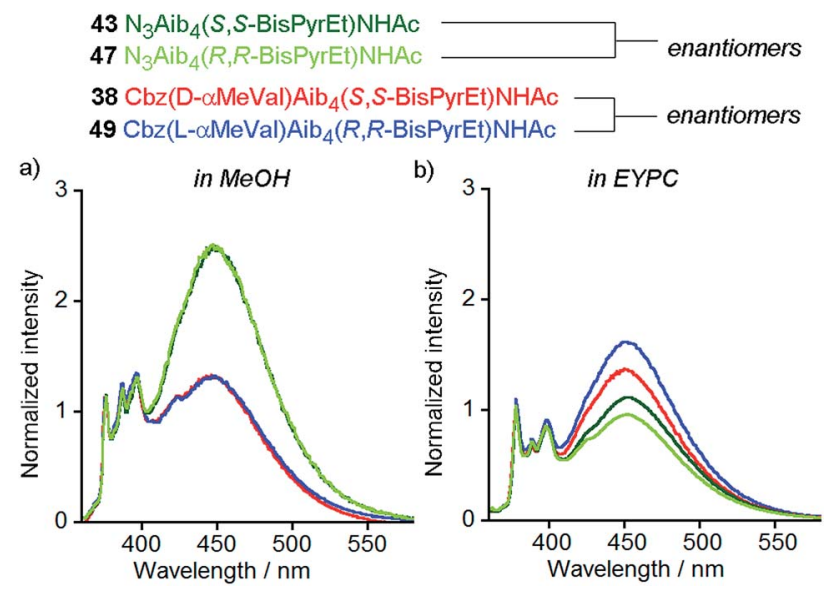

Fig. 9 Normalized fluorescence emission spectra (emission normalized to 1 at $377 \mathrm{~nm}$ ) for $\mathbf{4 3}$ (dark green line), 47 (pale green line), 38 (red line) and 49 (blue line) in (a) MeOH $(10 \mu \mathrm{M})$; (b) EYPC LUVs, $800 \mathrm{~nm}$ diameter at $1 \mathrm{~mol} \%(10 \mu \mathrm{M})$.

$E / M$ between diastereoisomers 38 and 37 in a bilayer $(\Delta(E / M)=$ -0.29 ), indicating chiral induction by the bilayer can be significant influence on conformation.

\section{Conclusions}

The synthesis and analysis of several classes of bis(pyren-1-yl) fluorescent probe has shown that 1,2-bis(pyren-1'-yl)ethylenediamines, readily made by an enantiospecific aza-Cope rearrangement, display promising features as probes of conformational change in oligomers. Ligation to the Cterminus of Aib foldamers was followed by acetylation of the free amino group, providing a versatile reporter of peptide conformation.

The acetamide of $(S, S)$-1,2-bis(pyren-1'-yl)ethylenediamine succeeded as a fluorescent reporter of conformation where earlier generations of probes did not for several key reasons. Unlike Cterminal pyrenylalanine residues, the chirality in these bis(pyren-1'-yl)ethylenediamine reporters did not overwhelm the remote chiral influence provide by the $\mathrm{N}$-terminal residue. The closer proximity of the two pyrene units gave substantially greater excimer fluorescence than designs that had the pyrene units spaced further apart. Acetylation of the C-terminal amine reduced the control exerted by the bis(pyren-1'-yl)ethylenediamine on the Aib foldamer, providing an optimized reporter that is more responsive to differences in screw-sense preference.

The optimized bis(pyrene) fluorescent reporter permits conformational interchange between $M$ and $P$ helicities in Aib foldamers to be monitored in real time in both organic solvents and bilayers. In bilayers, excimer fluorescence from the reporter group allowed the localization of foldamers in vesicle membranes to be confirmed by fluorescence microscopy. The synthesis of enantiomers of chiral peptide foldamers bearing this bis(pyrene) fluorescent reporter was used to provide a unique biophysical insight, revealing for the first time that the chirality of phospholipids in a bilayer can have a significant influence on the conformation of oligomers, such as foldamers and peptides, in the membrane.

The design of this probe permits rapid and continuous measurement of conformational change, a distinct advantage over previous probes that required monitoring by solid state ${ }^{19} \mathrm{~F}$ NMR spectroscopy. These advantages have been realized in the development of a functioning mimic of a $\mathrm{G}$ protein coupled receptor, which was able to undergo conformational change in a bilayer upon binding of a chemical signaling ligand. ${ }^{12}$ Using fluorescence to measure conformational change is also more amenable to studies of foldamers in cellular membranes, where cellular location and conformational switching can both be measured. The probe structure described in this work is a promising lead compound for such studies in cells.

\section{Conflicts of interest}

There are no conflicts to declare.

\section{Acknowledgements}

This work was supported by the European Research Council (Advanced Grant ROCOCO), the BBSRC (DTP studentship and grant BB/I007962) and the EPRSC (grants EP/N009134/1 and EP/ K039547).

\section{References}

1 (a) J. Solà, S. P. Fletcher, A. Castellanos and J. Clayden, Angew. Chem., Int. Ed., 2010, 49, 6836-6839; (b) T. Boddaert, J. Solà, M. Helliwell and J. Clayden, Chem. Commun., 2012, 48, 3397-3399; (c) L. Byrne, J. Solà, T. Boddaert, T. Marcelli, R. W. Adams, G. A. Morris and J. Clayden, Angew. Chem., Int. Ed., 2014, 53, 151-155; (d) B. A. F. Le Bailly and J. Clayden, Chem. Commun., 2014, 50, 7949-7952; (e) B. A. F. Le Bailly, L. Byrne, V. Diemer, M. Foroozandeh, G. A. Morris and J. Clayden, Chem. Sci., 2015, 6, 2313-2322; (f) J. Brioche, S. J. Pike, S. Tshepelevitsh, I. Leito, G. A. Morris, S. J. Webb and J. Clayden, J. Am. Chem. Soc., 2015, 137, 6680-6691; $(g)$ D. Mazzier, M. Crisma, M. De Poli, G. Marafon, C. Peggion, J. Clayden and A. Moretto, J. Am. Chem. Soc., 2016, 138, 8007-8018.

2 B. A. F. Le Bailly and J. Clayden, Chem. Commun., 2016, 52, 4852-4863.

3 (a) R. P. Hummel, C. Toniolo and G. Jung, Angew. Chem. Int. Ed., 1987, 26, 1150-1152; (b) M. Kubasik, J. Kotz, C. Szabo, T. Furlong and J. Stace, Biopolymers, 2005, 78, 87-95; (c) M. Kubasik and A. Blom, ChemBioChem, 2005, 6, 1187-1190.

4 J. Solà, G. A. Morris and J. Clayden, J. Am. Chem. Soc., 2011, 133, 3712-3715.

5 M. De Poli, L. Byrne, R. A. Brown, J. Solà, A. Castellanos, T. Boddaert, R. Wechsel, J. D. Beadle and J. Clayden, J. Org. Chem., 2014, 79, 4659-4675.

6 (a) J. Clayden, A. Castellanos, J. Solà and G. A. Morris, Angew. Chem., Int. Ed., 2009, 48, 5962-5965; (b) R. A. Brown, T. Marcelli, M. De Poli, J. Solà and J. Clayden, Angew. 
Chem., Int. Ed., 2012, 51, 1395-1399; (c) S. J. Pike, M. De Poli, W. Zawodny, J. Raftery, S. J. Webb and J. Clayden, Org. Biomol. Chem., 2013, 11, 3168-3176; (d) M. De Poli and J. Clayden, Org. Biomol. Chem., 2014, 12, 836-843.

7 R. A. Brown, V. Diemer, S. J. Webb and J. Clayden, Nat. Chem., 2013, 5, 853-860.

8 M. De Poli, W. Zawodny, O. Quinonero, M. Lorch, S. J. Webb and J. Clayden, Science, 2016, 352, 575-580.

9 B. Valeur, Molecular Fluorescence Principles and Applications, Wiley-VCH Verlag GmbH, 2001, vol. 8.

10 S. A. Denisov, Q. Gan, X. Wang, L. Scarpantonio, Y. Ferrand, B. Kauffmann, G. Jonusauskas, I. Huc and N. D. McClenaghan, Angew. Chem. Int. Ed., 2016, 55, 13281333.

11 K. P. Liem, G. T. Noble, S. L. Flitsch and S. J. Webb, Faraday Discuss., 2010, 145, 219-233.

12 F. G. A. Lister, B. A. F. Le Bailly, S. J. Webb and J. Clayden, Nat. Chem., 2017, 9, 420-425.

13 R. Krauss, H.-G. Weinig, M. Seydack, J. Bendig and U. Koert, Angew. Chem., Int. Ed., 2000, 39, 1835-1837.

14 G. Bains, A. B. Patel and V. Narayanaswami, Molecules, 2011, 16, 7909-7935.

15 (a) H. Lettré, K. Buchholz and M. Fernholz, Z. Physiol. Chem., 1940, 267, 108-114; (b) S. Egusa, M. Sisido and Y. Imanishi, Macromolecules, 1985, 18, 882-889; (c) R. Goedeweeck and F. C. De Schryver, Photochem. Photobiol., 1984, 39, 515-520; (d) H. Mihara, Y. Tanaka, T. Fujimoto and N. Nishino, J. Chem. Soc., Perkin Trans. 2, 1995, 1133-1140; (e) H. Mihara, S. Lee, Y. Shimohigashi, H. Aoyagi, T. Kato, N. Izumiya and T. Costa, Int. J. Pept. Protein Res., 2009, 30, 605-612; (f) A. Szymańska, W. Wiczk and L. Lankiewicz, Amino Acids, 2001, 21, 265-270; $(g)$ I. Alves, S. Cowell, Y. S. Lee, X. Tang, P. Davis, F. Porreca and V. J. Hruby, Biochem. Biophys. Res. Commun., 2004, 318, 335-340.

16 M. Sisido and Y. Imanishi, Macromolecules, 1985, 18, 890894.

17 (a) Y. Inai, M. Sisido and Y. Imanishi, J. Phys. Chem., 1990, 94, 2734-2735; (b) M. Sisido, S. Egusa, A. Okamoto and Y. Imanishi, J. Am. Chem. Soc., 1983, 105, 3351-3352.

18 (a) M. Goedeweeck, M. Van der Auweraer and F. C. De Schryver, J. Am. Chem. Soc., 1985, 107, 2334-2341; (b) R. Goedeweeck, F. Ruttens, F. López-Arbeloa and F. C. De Schryver, Biopolymers, 1987, 26, 1833-1857.
19 (a) S. Egusa, M. Sisido and Y. Imanishi, Macromolecules, 1985, 18, 882-889; (b) Private Communication, Prof. Masahiko Sisido, Okayama University.

20 J. Solà, M. Helliwell and J. Clayden, J. Am. Chem. Soc., 2010, 132, 4548-4549.

21 M. De Poli, M. De Zotti, J. Raftery, J. A. Aguilar, G. A. Morris and J. Clayden, J. Org. Chem., 2013, 78, 2248-2255.

22 (a) U. Koert, R. Krauss, H.-G. Weinig, C. Heumann, B. Ziemer, C. Mugge, M. Seydack and J. Bendig, Eur. J. Org. Chem., 2001, 2001, 575-586; (b) H. G. Weinig, R. Krauss, M. Seydack, J. Bendig and U. Koert, Chem.-Eur J., 2001, 7, 2075-2088; (c) R. Krauss and U. Koert, Synlett, 2003, 5, 598-608.

23 A. Breuning, R. Vicik and T. Schirmeister, Tetrahedron: Asymmetry, 2003, 14, 3301-3312.

24 H. Kim, Y. Nguyen, C. P.-H. Yen, L. Chagal, A. J. Lough, B. M. Kim and J. Chin, J. Am. Chem. Soc., 2008, 130, 1218412191.

25 E. L. Doyle, C. A. Hunter, H. C. Phillips, S. J. Webb and N. H. Williams, J. Am. Chem. Soc., 2003, 125, 4593-4599.

26 G. T. Noble, F. L. Craven, J. Voglmeir, R. Šardzík, S. L. Flitsch and S. J. Webb, J. Am. Chem. Soc., 2012, 134, 13010-13017.

27 M. G. Lizio, V. Andrushchenko, S. J. Pike, A. D. Peters, G. F. S. Whitehead, I. J. Vitórica-Yrezábal, S. T. Mutter, J. Clayden, P. Bouř, E. W. Blanch and S. J. Webb, Chem.Eur J., 2018, 24, 9399-9408.

28 T. Ishigami, K. Suga and H. Umakoshi, ACS Appl. Mater. Interfaces, 2015, 7, 21065-21072.

29 A. Sorrenti, M. Diociaiuti, V. Corvaglia, P. Chistolini and G. Mancini, Tetrahedron: Asymmetry, 2009, 20, 2737-2741.

30 Y. Okamoto, Y. Kishi, T. Ishigami, K. Suga and H. Umakoshi, J. Phys. Chem. B, 2016, 120, 2790-2795.

31 T. Hitz, M. Blocher, P. Walde and P. L. Luisi, Macromolecules, 2001, 34, 2443-2449.

32 I. C. Pintre and S. J. Webb, Adv. Phys. Org. Chem., 2013, 47, 129-183.

33 H. Nakagawa and K.-I. Yamada, Chem. Pharm. Bull., 2005, 53, 52-55.

34 H. Nakagawa, M. Onoda, Y. Masuoka and K.-I. Yamada, Chirality, 2006, 18, 212-216.

35 F. Ceccacci, G. Mancini, P. Rossi, P. Scrimin, A. Sorrenti and P. Tecilla, Chem. Commun., 2013, 49, 10133-10135. 